\title{
Turismo religioso, adventismo e lugares de memória
}

\author{
Religious Tourism, Adventism and Places of Memory
}

Rodrigo Follis *

\begin{abstract}
Resumo
Halbwachs coloca três possibilidades de constituição da memória oficial de um grupo religioso, a saber 1) um evento; 2) uma pessoa; ou, 3) um local geográfico. Tal autor considera que o espaço geográfico sempre será a melhor das opções, devido a sua materialidade ao fornecer uma construção de memória menos efêmera. Assim, é possível enfatizar a importância das mais diversas denominações cristãs de focarem seus esforços em fortalecer o turismo religioso. Como estudo de caso, e a partir dessa base teórica, o presente artigo analisa o adventismo do sétimo dia, através de sua revista oficial, a Revista Adventista, em busca de se perceber como o periódico, nos últimos tempos, tem articulado a importância de lugares de memória do movimento e tem se aberto para o turismo religioso, mesmo que de maneira ainda embrionária. Conclui-se com um alerta de que a memória constituinte adventista, assim como de qualquer outro grupo religioso, precisa ser constantemente repensada e retransmitida aos membros. E os locais de memória, em conjunto com o turismo religioso, podem ajudar para a manutenção desse projeto.
\end{abstract}

Palavras-chave: Turismo religioso; Adventismo; Lugares de memória; Halbwachs.

\begin{abstract}
Halbwachs poses three possibilities of constitution of a religious group's oficial memory, namely 1) an event; 2) a person; o, 3) a geographical location. That author considers that a geographical space will always be the best option, due to its materiality to provide a less ephemeral memory construction. Thus, it is possible to emphasize the importance that the most diverse Christian denominations focus their efforts in strengthening religious tourism. As a case study, and within this theoretical basis, this article analyzes Seventh-day Adventism through its official magazine in Brazil, Revista Adventista, in an attempt ${ }^{1}$ to understand how that magazine has recently articulated the importance of places of memory of the movement and has opened itself to religious tourism, even if in an embryonic way. It concludes with an alert that the Adventist constituent memory, as well as any other religious group, must be constantly reweighed and retransmitted to the members. And memory locations, along with religious tourism, can help maintain this project.
\end{abstract}

Keyword: Religious tourism; Adventism; Places of Memory; Halbwachs.

\footnotetext{
Artigo submetido em 19 de fevereiro de 2018 aprovado em 17 de abril de 2018.

* Doutor em Ciências da Religião pela Universidade Metodista de São Paulo. É docente da Faculdade de Teologia e do Curso de Comunicação Social do Unasp-EC. País de origem: Brasil. E-mail: rodrigo.follis@unasp.edu.br
} 


\section{Introdução}

Maurice Halbwachs (2009; 2004; 1994; 1971) foi um importante teórico para a construção dos estudos da memória coletiva e, mesmo não tendo essa intenção direta, pode ser utilizado como fonte de grandes discussões para a teorias do funcionamento da religião. Para esse autor, quando a religião entrava na pauta, era sempre dentro da perspectiva maior da busca por entender o mecanismo da memória, a qual está inserida a religião, mas não se resume a ela (na verdade, seria a religião que se resumiria à memória).

Para realmente iniciar nossa conversa, cabe salientar que Halbwachs nunca clamou para si o título de estudioso da religião. E, talvez por não se considerar um teórico da religião, tenha sido esquecido pelos estudiosos de tal campo. Aqui está uma boa diferença do pensamento desse autor em comparação com os durkheimianos, linha que ele seguia, para os quais a religião era vista como um dos fatores primordiais para a construção da coesão social (RIVERA, 2010a).

Para Halbwachs, segundo nos lembra Santos (2003, p. 37), devido a sua linha durkheimiana, apenas o estudo empírico que busca entender como os grupos transmitem suas memórias é que explica "os interesses, formas de trabalho, serviços e situações assumidas por esses mesmos grupos”. É através dessa base epistemológica que ele defendeu que "o consumo de bens entre trabalhadores não poderia ser determinado nem pela renda do trabalhador, nem pela sua inserção na produção, mas sim pelos elos concretos de solidariedade que se formavam entre eles" (SANTOS, 2003, p. 37).

Tais elos seriam a maneira como os indivíduos se unem aos grupos devido a uma memória comum. É preciso pensar o objeto a ser pesquisado nessa relação e não primariamente em suas abordagens históricas. Para entendermos o funcionamento de um grupo religioso é preciso pensar como seus membros se articulam com os eventos e locais históricos e de que maneira se processa o desenvolvimento da intepretação desses eventos e locais a partir da perspectiva do 
grupo em questão. Essa interpretação pode ser chamada de a versão oficial da memória instituída, a qual servirá como guia para os crentes do grupo. Dessa maneira, seria formada a "comunidade afetiva", a qual não age coercitivamente e é responsável pela unificação social. Vale deixar claro que, entendemos memória como o hábito humano de colecionar fatos construídos de maneira social. Ou seja, o ser humano só teria a capacidade de se recordar de algo devido a estar, mesmo que inconscientemente, associado a uma ou mais correntes de pensamentos coletivos.

Pois bem, dada essa introdução, cabe agora dizer que nosso objetivo no presente estudo é pensar a questão da memória afetiva aplicada na prática do turismo religioso em um caso concreto vivido na Igreja Adventista do Sétimo Dia (IASD) brasileira. Se acertarmos a já clássica definição de Dias (2003), entenderemos que turismo religioso é obtido quando a fé é a principal razão de uma determinada viagem. Ou seja, quando "pessoas que se deslocam por motivações religiosas e/ou para participarem em eventos de caráter religioso”. Incluímos nesse grupo as "romarias, peregrinações e visitação a espaços, festas, espetáculos e atividades religiosas" (DIAS, 2003, p. 17). Levando em conta as seis categorias de turismo religioso descritas por Dias (2003), o presente material abordará apenas a segunda: "espaços religiosos de grande significado históricocultural". ${ }^{2}$ Nossa intenção é entender a relação do adventismo brasileiro, dentro das páginas da Revista Adventista 3 , buscando como ela descreve um dos locais que o grupo considera como espaço de grande importância histórico-cultural e religioso.

Sobre o adventismo, não é nossa intenção produzir toda uma explicação sociológica, histórica ou teológica sobre tal grupo social. Cremos que, embora ainda

\footnotetext{
${ }^{2}$ Dias (2003) categoriza em seis possibilidades as diferentes formas de turismo religioso, a saber: a) santuários de peregrinação; b) espaços religiosos de grande significado histórico-cultural; c) encontros e celebrações de caráter religioso; d) festas e comemorações em dias específicos; e) espetáculos artísticos de cunho religioso; f) roteiros de fé. Essa lista, em nossa visão, contempla catolicismo, protestantismo ou qualquer outra forma de religiosidade, sendo apenas preciso se respeitar as peculiaridades de cada grupo.

${ }^{3}$ A revista em questão é o periódico oficial do movimento no Brasil, publicado pela editora de tal igreja por mais de 100 anos, tendo grande distribuição até hoje em todos os níveis denominacionais da IASD.
} 
se necessitando de uma necessária ascensão na quantidade, existem materiais excelentes que já fazem isso (SCHÜNEMANN, 2002; SCHWARZ; GREENLEAF, 2016; GREENLEAF, 2011; NOVAES; FOLLIS, 2016). Entretanto, como o grupo ainda é pouco conhecido na comunidade acadêmica geral, algumas questões precisaram ser explicadas para, então, procedermos com as devidas análises que realmente nos interessam.

Já introduzimos brevemente a sociologia da memória de Halbwachs (2009; RIVERA, 2010a), mas é preciso também a discutir ainda mais. Para esse autor, "a especificidade do fenômeno religioso dá-se pela capacidade de se estabilizar em cima de uma fidelização às origens e à tradição. Visando a garantir sua legitimidade, estabelece-se uma memória autorizada" (CAMURÇA, 2011, p. 205). Ou seja, a crença religiosa é uma memória religiosa, modificada a partir de rupturas sociais. Não cabe discutir se elas se fazem certas ou erradas, por isso nos focamos apenas em entender o processo desse fazer e não discutir sua validade.

Como Halbwachs $(1994 ; 2004)$ argumentaria, as inúmeras mudanças sociais da religião funcionam com a ilusão de uma "não mudança" (RIVERA, 2010a, p. 78). O que isso quer dizer? Para continuar a existir, a religião se apega a um imperativo de continuidade. Em outras palavras, o que se crê hoje possui várias diferenças com a crença do passado, mas mesmo assim consegue se remeter às origens do grupo religioso. A religião muda em um processo de adaptação dialógica com o contexto sociocultural, mas, ao mesmo tempo, precisa ter uma aura de continuidade. "A força das crenças religiosas reside na dinâmica da memória e de sua transmissão como um processo complexo que percebe os fatos originais em estado de preservação mesmo em meio às suas transformações" (CARMUÇA, 2011, p. 205; RIVERA, 2010a, p. 82).

Acreditamos que uma das formas, tal como argumentaremos ao decorrer do presente trabalho, de se transmitir a memória coletiva de um grupo social é o investimento em locais de memória e no turismo religioso para tais locais. Dada a 
estrutura de esquecimentos e recordações, provindas da transmissão da memória, qualquer autoridade religiosa precisa de um poder institucional para assegurar a continuidade da memória própria daquele grupo (HERVIEU-LÉGER, 2008). O poder religioso tem como tarefa regular as tensões estabelecendo uma autoridade normatizadora que legitime a tradição e a transmissão. É possível definir o propósito da transmissão como um processo que visa principalmente a "assegurar a socialização dos indivíduos e dos grupos no interior desse quadro institucionalmente regulado, integrando, de forma equilibrada, os diferentes registros (comunitário, ético, emocional e cultural) de identificação com a linhagem religiosa” (HERVIEU-LÉGER, 2000, p. 45-46). A relação de poder se liga às questões de transmissão da memória, não devendo ser vista em separado, mas como uma forma de constituição da crença. Aqui cabe uma questão metodológica, como será possível encontrar na Revista Adventista as relações de transmissão e de construção dos lugares da memória vivenciados pelo adventismo brasileiro, que podem mostrar algum tipo de turismo religioso praticado pelo grupo em questão?

\section{Proposta teórica e metodológica}

Através do conceito de Durkheim (2003a; 2003b) quanto ao espírito de um grupo religioso, Alves (2005, p. 36) argumenta que a ideia que o grupo faz de si mesmo é um dos conceitos fundamentais a se levar em conta para entendermos o seu comportamento. E foi justamente isso que decidimos buscar no adventismo brasileiro, associando a emergente discussão acerca do turismo religioso. O reflexo que o adventismo tem de si próprio pode ser encontrado no uso que ele faz das mais diversas mídias em seu processo de transmissão da memória religiosa. Nessa análise, podemos compreender a consciência coletiva, a qual consideramos mais do que apenas um epifenômeno "de sua base morfológica, da mesma forma como a consciência individual é algo mais que uma simples floração do sistema nervoso” (DURKHEIM, 2003a, p. 470-471). Halbwachs argumenta que "o funcionamento da memória individual não é possível sem esses instrumentos [da memória coletiva] que são as palavras e as ideias, que o indivíduo não inventou, mas toma 
emprestado do seu ambiente". Ele nos lembra que, "para evocar seu próprio passado, em geral a pessoa precisa recorrer às lembranças de outras” (HALBWACHS, 2009, p. 72; CASADEI, 2010). Nessa lógica, o grupo faz o indivíduo; o qual não é determinado, mas, é influenciado ou melhor, articulado.

Essa perspectiva teórica justifica o uso de documentos oficiais do grupo em lugar de se entrevistar os membros e crentes. Não que a entrevista com indivíduos deva ser descartada, mas cremos que na linguagem oficial usada teremos a opção da qual os indivíduos se valem para a decisão de suas crenças e essa, por estar registrada, acaba por poder ser analisada e comparada ao longo dos anos. Alves (2005, p. 41) completa dizendo que: "o primeiro critério me é dado pelo próprio objeto que busco elucidar: o espírito de um grupo, os seus desejos fundadores, a sua estruturação da realidade. Tentarei descobrir o espírito na forma como ele se encontra presente na linguagem”. Mas qual linguagem? Quais vertentes podemos usar para interpretá-la? E em que local ela pode ser encontrada?

Vamos nos focar na última pergunta. Nosso corpus de interesse une questões técnicas/instrumental e teológicas, e se nosso interesse se volta para a análise do uso da mídia no adventismo brasileiro e do processo de transmissão religiosa dali derivado; a própria Revista Adventista, periódico oficial do movimento, apresenta-se como a melhor fonte documental para se pesquisar essas relações. Os meios de comunicação, tal como a Revista Adventista, desempenham "um papel crucial na produção de uma ideia de história e memória”, e o fazem quando mediam as relações "dos sujeitos com as transformações do seu cotidiano”, ao produzir "sentidos para os processos históricos" da "mesma forma que participam da constituição das próprias subjetividades” (RIBEIRO; FERREIRA, 2007, p. 7).

Mas qual o motivo de colocarmos o turismo religioso dentro de toda a discussão aqui empreendida? Afinal, em um periódico é possível se encontrar múltiplas discussões e exemplos que sirvam para ilustrar o grupo social e religioso 
envolvido na publicação, promoção e leitura daquelas páginas. O presente artigo teve sua origem durante a escrita de uma parte de nossa tese doutoral (FOLLIS, 2017) quando, quase no final da pesquisa, nos deparamos com o assunto do presente material. Essa questão era secundária para nossa tese, devido a própria problemática que naquele momento nos importava, ficando a ser repensada em um momento posterior. Assim, apesar de muitos achados citados lá se encontrarem no presente artigo, cremos que a discussão que aqui se encontra seja totalmente inédita, por ter sido expandida e rearticulada, ganhando profundidade e foco. $\mathrm{E}$ foi esse achado ocorrido lá atrás que nos motivou a pensar o turismo religioso como uma possibilidade, mesmo que embrionária, de manutenção e transmissão da memória oficial do movimento adventista. Devido a identidade e a memória de tal movimento estar intimamente ligada aos EUA do século 19 (FOLLIS, 2017), o Brasil do século 20 parece ainda ter interesse nessa história, a ponto de crentes viajarem para encontrar tais raízes.

A metodologia utilizada neste artigo também faz eco à construída em nosso trabalho doutoral, seguindo o mesmo tipo de análise da Revista Adventista que empreendemos lá. Procuramos e catalogamos a expressão Battle Creek em todos os exemplares da revista (1906 - 2010). Os achados foram contabilizados em uma tabela e posteriormente analisados a partir de uma perspectiva qualitativa. Também pesquisamos a cidade de Gaspar Alto, RS, mas os resultados foram bem menores e poucos se referiam realmente a viagens turísticas, e por isso nos focamos mais na primeira do que na segunda.

A lógica defendida por Strauss e Corbin (2008) ajuda a explicar o motivo de partirmos em uma busca tão específica quanto a de nomes de cidades. Tais autores sugerem que primeiramente possamos conhecer o material a ser pesquisado para, depois, construir as categorias a serem buscadas e analisadas. Isso se dá justamente para evitar que tenhamos um processo de pesquisa enviesado por categorias previamente escolhidas. Como anteriormente conhecemos a fundo 
grande parte do material da revista em questão, neste artigo eles necessitam apenas serem melhores explorados, catalogados e analisados.

Esse processo acabou por nos capacitar para pesquisas mais específicas, com os dados encontrados anteriormente. Após essa categorização, analisamos o material tanto pela análise de conteúdo (BARDIN, 1977; FRANCO, 1986; ROCHA e DEUSDARÁ, 2005) como também pela análise de discurso (GODOY, 1995; GILL, 2002; MAGALHÃES, 2009; ORLANDI, 1987; WILSON, 2003). Passaremos a seguir em busca de uma análise que una a memória como entendida por Halbwachs ao atual conceito de Turismo Religioso. Discutiremos propriamente os achados na Revista Adventista e analisaremos suas implicações simultaneamente, mostrando como eles se enquadram na discussão aqui empreendida.

\section{Conceitos básicos da memória religiosa e sua aplicação ao turismo religioso}

Halbwachs (2009), principalmente na obra A memória coletiva, enfocará as colunas que nos ajudam a localizar os fundamentos da memória coletiva. Elas são vistas de múltiplas maneiras e locais, tais como no "patrimônio arquitetônico e seu estilo", também nas "paisagens, datas e personagens históricas de cuja importância somos incessantemente relembrados, [n]as tradições e costumes, certas regras de interação, [n]o folclore e [n]a música, e, por que não, [n]as tradições culinárias” (POLLAK, 1989, p. 3; 1992). E cada uma dessas possibilidade de construções e perpetuações da memória eram chamadas, pelo autor, de quadros sociais da memória. Assim, quando viajamos de um local para o outro, nunca estamos sozinhos, seremos acompanhados por toda a construção coletiva que fizeram do lugar que estamos ou para o qual vamos.

Uma das mais conhecidas parábolas escritas por Halbwachs é a do "solitário de Londres", na qual ele narra a história de um visitante que anda sozinho em Londres pela primeira vez, mas que traz consigo conselhos, histórias, recordações e conhecimentos acumulados de outras pessoas ou grupos, assim, ao andar por 
Londres, mesmo que sozinho fisicamente, ele não está só. E se ele identifica os monumentos, entende a lógica da cidade, sabe como conversar com as pessoas que encontra, tem possibilidade de comprar algo que lhe chame a atenção, ele o faz dentro dessa perspectiva de que como indivíduo ele está sempre acompanhado pelo coletivo, criador de todas essas estruturas.

Afinal, os "indivíduos não recordam sozinhos, quer dizer, eles sempre precisam da memória de outras pessoas para confirmar suas próprias recordações” (SANTOS, 2003, p. 43; ver DOUGLAS, 1998; RIOS, 2013; NORA, 1993). Dessa maneira, um monumento ou espaço religioso, a ser contemplado pelo religioso que se desloca para tal ato, indica que atrás deles existiu e existe toda uma construção de memória coletiva.

Caminhando para conceitos mais pragmáticos, em Halbwachs (1971, p. 124; ver RIVERA, 2010a, p. 85), uma verdade religiosa, para se fixar "na memória de um grupo" precisará se apresentar "sob a forma concreta de um [1] acontecimento, de [2] uma figura pessoal ou de [3] um lugar”. Devido a sua estabilidade, o local geográfico [3] geralmente é o melhor para a consolidação da memória autorizada de uma coletividade. Todavia, ele não deve ser encarado como motivador principal nem como fator único. Halbwachs dedica um livro inteiro sobre a Terra Santa para mostrar como ocorre a relação de apropriação do espaço sagrado e sua articulação com a memória do cristianismo ao decorrer dos tempos.

O interessante é notar a importância do local físico para a religião. E isso pode ser visto com um exemplo que consideramos didático. Diferente da família, se encarada como um quadro social da memória, o religioso precisará de uma permanência e uma aderência muito maior para se consolidar e conseguir produzir os efeitos esperados. Aqui um exemplo se faz necessário. Na família apenas a simples existência do papel basta para auxiliar em nossa identidade, não importando ser um bom pai ou um bom filho (essa relação se dá devido a sua não busca por uma verdade definitiva, nenhuma família se preocupada em ser 
verdadeira, ontologicamente dizendo, enquanto que, para isso, a família do vizinho precisará estar errada. Se faz possível existir na sociedade duas famílias ou mais consideradas verdadeiras, ou melhor dizendo, saudáveis - já que essa adjetivação faria mais sentido seguindo essa mesma lógica).

Entretanto, na religião, é preciso mais do que um título para a existência de uma continuidade, que dê a impressão de ser ela vinda de uma tradição anterior, possivelmente sem começo e nem fim, pois se localizaria a religião junto com Deus na eternidade. E aqui está um dos seus grandes diferenciais, ela demanda uma continuidade que justifique a motivação da crença em um sistema e não em outro. A busca é pela verdade, e não se pode admitir que o grupo um dia esteve errado sobre sua crença precisando modifica-la por causa disso. Diferente da religião, se o meu núcleo familiar for ruim e me trouxer sofrimento, não precisarei colocar em xeque toda a estrutura familiar em detrimento a isso (ou seja, mesmo se fui um péssimo filho, continuarei a ser filho).

Após entender a importância de se buscar a verdade, é possível perceber o porquê do local geográfico ter supremacia para justificar a continuidade religiosa: ele possui uma materialidade mais visível e de difícil modificação, o que transfere tais características à verdade agregada a ele. Através dele é possível ver, tocar, sentir e, dessa maneira, questionar seu valor como fato social. Uma religião que esteja ligada a um evento ou mesmo a uma pessoa, tem uma fragilidade maior, principalmente a partir da segunda e terceira geração de crentes. Pessoas e eventos, apesar de únicos e de não se repetirem (aspectos igualmente importantes para a formação da memória religiosa ou mesmo familiar), são efêmeros.

Como lembra Rivera (2010a, p. 86; 2010b) “o espaço efêmero não teria qualquer sentido, e a transformação repentina do lugar comum implica novos desafios para a memória do grupo”. O que podemos inferir é que quanto mais perene a base na qual a religião se assentar, maior será sua capacidade de enunciarse portadora de uma história que a conduza como a opção verdadeira a se 
acreditar. A religião precisa dessa perenidade para sua continuação, mas também se utiliza de uma ruptura para sua fundação.

Aqui se faz importante dois aspectos, no primeiro temos a importância da religião como contracultural, mas no outro extremo, temos um outro aspecto que pode soar paradoxal embora não o seja: a religião precisa manter-se como uma entidade imutável. Essa relação é bem trabalhada por Halbwachs (1971, p. 189, tradução livre; ver RIVERA, 2010a; HERVIEU-LÉRGER; WILLAIME, 2009) quando ele afirma que "se o cristianismo jamais tivesse se apresentado como a continuação, em certo sentido, da religião judaica, podemos nos perguntar se ele teria se constituido como religião". Por um lado, para o cristianismo existir como religião, dentro da realidade sócio-histórica de seu nascimento, era preciso se posicionar como diferente do judaísmo (religião até então considerada como verdadeira). Entretanto, para essa dinâmica ser completa, foi preciso existir traços de continuidade do discurso religioso, assim, o cristianismo apregoa ser a concretização do judaísmo, no Messias esperado. Como podemos ver, continuidade e rupturas trabalham lado a lado. Uma justificando a outra na dinâmica religiosa. $\mathrm{O}$ cristianismo seria filho direto da memória do judaísmo (HERVIEU-LÉGER, 2009).

É claro que, por maior que venha a ser a influência do espaço geográfico, ele só será plenamente entendido quando pensado a partir da lógica do espaço social, que nada mais é do que a (re)articulação feita pelos crentes do presente a partir dos dados fornecidos, todos provindos do passado e repensados segundo as necessidades atuais. Halbwachs (1971) argumenta que espaços geográficos antes dedicados a religião judaica, agora são (re)articulados para explicarem acontecimentos a serem rememorados pelo cristianismo. Como lembra o autor, com o passar do tempo esses espaços mudam segundo as necessidades de cada época e de cada denominação que se considera fiel transmissora da verdade cristã. Se a ênfase em determinado período ou grupo cristão está na morte de Cristo na cruz, o espaço mais lembrado será o que se julga ter ocorrido a crucificação. Já, em outro período, no qual se foque mais a ressureição, o espaço lembrado será aquele 
em que se acredita estar o túmulo-vazio. Com exemplos históricos que demonstram as ênfases e modificações nos espaços sagrados ao decorrer dos séculos, o autor constrói o pensamento da importância do local para a memória.

Essa manutenção da memória autorizada de um grupo não está isenta de modificações em suas ênfases, estruturas e conceitos. Muito pelo contrário, tanto Halbwachs (2004; ver 1994; 1991) como Hervieu-Léger (2005; ver HERVIEULÉGER; WILLAIME, 2009) argumentam existir rupturas importantes nos padrões outrora usados. Justamente, é a ilusão de uma permanência, mesmo quando vivemos uma ruptura, o maior trunfo da religião. O cristianismo rompe com o judaísmo em um combate pela veracidade de sua pregação (apenas uma dessas religiões pode ser verdadeira; Ou Jesus é o messias ou ele não o é. Judaísmo ou cristianismo devem ser escolhidos a partir dessa discussão eliminatória). Mas, mesmo o cristianismo rompendo, existe a necessidade de que sua pregação pareça uma continuidade do judaísmo, protegendo o novo grupo e o crente de uma ruptura completa ao contexto já aceito e vivido.

Aqui voltamos a discussão feita anteriormente quanto a importância de, na religião, existir a necessidade de uma perenidade. Isso se dá devido a precisão do grupo religioso minimizar conflitos quanto a verdade pregada, pois uma ruptura completa causaria desconfiança por partes dos crentes. Na Palestina do primeiro século, uma religião que pregasse que "um messias não seria necessário" teria mais problemas em ser aceita do que aquela que indicasse quem seria o messias. O cristianismo valida o judaísmo ao dizer que Cristo é o Messias, pois para se sustentar como religião é preciso se partir dessa promessa judaica. Enfatiza-se de maneira preponderante a continuidade apesar de existir uma certa ruptura dessas duas teologias. Através dessa compreensão mais ampla, é possível entender a preocupação de Rivera (2010a; 2010b) sobre o local geográfico mantido pelo Protestantismo. Ao lembrarmos que em tal grupo não se tem a ênfase em peregrinações, em relíquias ou mesmo em recordações geográficas, faz sentido se 
perguntar sobre qual seria o substituto do espaço geográfico usado pelo protestantismo para se manter como memória. Para esse autor,

No protestantismo, que pelos seus princípios sempre se recusou a aceitar qualquer tipo de representação ou imagem, é de supor que conseguiu manter a ilusão da permanência por outros caminhos; por exemplo, a fidelidade ao texto sagrado, considerado eterno e imutável. O protestantismo se remeteu às suas origens por meio da Bíblia e sem o auxílio das representações [geográficas, portanto, consideradas mais perenes]. [...]. Talvez seja uma das razões pelas quais o protestantismo fragmentou-se rapidamente. (RIVERA, 2010a, p. 87-88).

E porque essa fragmentação ocorreria? Na falta de uma base geográfica para ancorar sua crença, parece existir duas opções para tais grupos religiosos (aqui se inclui não apenas os grupos dos Protestantes, mas também os Pentecostais e Neopentecostais); 1) tais religiões se utilizam de algum outro meio para construir sua base de continuidade ou 2) elas não precisam de tais construções para manter suas memórias. Como consideramos a lógica de Halbwachs, não achamos viável a segunda opção, pois nenhuma identidade de grupo ou individual pode ser construída fora do espaço social. Restando a primeira opção, se não em locais geográficos, esses grupos religiosos usam outros meios, tal como o texto bíblico e religioso, apresentado na argumentação de Rivera (2010a; 2010; 2007).

O problema de se basear em um texto, por mais imutável que ela possa parecer (e a Bíblia tem pelo menos três mil anos de história para servir de fundamentação a essa ideia), é que as formas e técnicas de intepretação são bem mais fluídas do que às de um local geográfico (e são muitas as correntes e escolas de intepretação). Constrói-se em bases efêmeras aquilo que se esperava consistente e fonte de continuidade. Essa é a preocupação levantada por Rivera (2010a; 2005) ao afirmar que o protestantismo se fragmentou. Talvez uma solução possível para esse impasse seria o protestantismo criar aquilo que Pollak (1989) vai chamar de lugares de memória. Não se substituiria o texto bíblico, mas se acrescentaria locais específicos que ajudariam na construção e na transmissão da memória coletiva do grupo. O que poderíamos chamar de construções didáticas, pois elas serviriam para 
passar a perspectiva do grupo, nunca para a substituir ou elas mesmas se tornarem o centro da adoração e da memória.

Cremos que, não de maneira intencional, o adventismo construiu algo parecido com o que chamamos aqui de um lugar de memória, mas essa construção, devido a importância que o grupo dá a sua formação e história inicial, estão quase que totalmente localizados nos EUA, nas casas e locais importantes que se pode datar e recontar a memória formativa do movimento. E, pode-se notar sua importância no adventismo brasileiro a partir da nossa pesquisa encontrada na Revista Adventista.

\section{Lugares de memória no adventismo: o texto e a geografia}

O início da utilização das publicações impressas no adventismo brasileiro não foi diferente do encontrado nos EUA. A estratégia da igreja estaria ligada diretamente àquela que os pioneiros do movimento já haviam realizado, dessa forma, não é de se estranhar a grande identificação que os editores brasileiros, tanto de livros como de revista, possuem com as produções estadunidenses (FOLLIS, 2017). Por aqui o foco inicial foi na divulgação de materiais impressos para imigrantes europeus que viviam na região; uma estratégia de comunicação adaptada à língua e cultura dos imigrantes, em sua maioria já protestantes. Nesse sentido temos a revista Hausfreund (Amigos do lar) e o livro Gedanken Über das Buch Daniel (Comentário sobre o livro de Daniel), que influenciou Guilherme Belz, um dos primeiros adventistas brasileiros, a reconhecer o sábado como dia de descanso. É relevante pensar que a forma de estruturação da memória adventista se dá quase sempre embalada no texto escrito, em semelhança aos grupos protestantes que precedem de um local geográfico para a construção de sua memória religiosa.

Por outro lado, uma das histórias mais difundidas é a da revista, em alemão, Stimme der Waheit [A Voz da Profecia]. Com frequência se conta a história dela 
ter sido enviada, sem destinatário, para o porto de Itajaí, sendo encontradas por acaso (BORGES, 2001; COSTA, 2003, p. 48). É preciso ter em mente que

os livros adventistas procuram apresentar a história da IASD no Brasil como tendo um início providencial, antes de qualquer iniciativa da Associação Geral nos Estados Unidos. [...]. Este episódio, contudo, não foi documentado. As narrativas foram passadas oralmente pela tradição e há algumas diferenças entre elas, mas conservam uma matriz comum. (SCHÜNEMANN, 2002, p. 155).

A história fundamente do adventismo no Brasil ganha contornos sobrenaturais. Fundamentados mais na história oral, acabam por ser celebrados posteriormente como uma das evidências de que Deus estaria guiando a missão no Brasil. Encontramos esse relato algumas vezes na revista, como em Fevereiro de 1950 (p. 8):

Foi precisamente em Gaspar Alto que, de modo tão interessante, se estabeleceu o primeiro núcleo de adventistas no Brasil. O pastor Westpjal, ao visitá-los, tomou conhecimento, por intermédio dos néo-conversos, de como a mensagem penetrou pela primeira vez em nosso País: "Um vapor deixou, em 1884, no porto de Itajaí (Sta. Catarina) uma revista alemã. Esta caiu nas mãos de um professor de Brusque. Nesta revista leu que se alguém desejasse mais literatura poderia recebê-la escrevendo à Sociedade Internacional de Tratados. Escreveu e recebeu certa quantidade de revistas em alemão, mensalmente. Vendeu algumas destas de casa em casa e usou o dinheiro para beber álcool. Depois trocou revistas por bebida, numa venda (REVISTA ADVENTISTA, Fevereiro de 1950, p. 8).4

O texto narrado dá a entender que o jovem apenas estaria interessado no dinheiro e não no conteúdo ali encontrado. Todavia, posteriormente o livro é encontrado e pessoas começam a se converter. É importante notar que esse processo ocorre antes da formalização da igreja no Brasil, com o envio de missionários e dos primeiros vendedores de livros da denominação. Através desses materiais, o autor argumenta que o Espírito Santo está à frente de toda a pregação do movimento no Brasil, desde o seu início.

\footnotetext{
${ }^{4}$ Lembramos que as referências da Revista Adventista não foram disponibilizadas junto às demais referências bibliográficas, ao fim do presente artigo, isso se dá pelo fato de considerarmos a revista corpus e não fonte referencial. Todas as edições, em pdf pesquisável, como já mencionado, podem ser acessadas gratuitamente a partir do seguinte endereço eletrônico: www.revistaadventista.com.br
} 
Até aqui temos um protestantismo clássico, apegado ao texto. Entretanto, é possível ver de maneira frequente na Revista Adventista a citação da cidade de Gaspar Alto, SC, como a primeira igreja adventista do Brasil. A cidade sempre é relembrada, como se percebe na citação acima, devido a um importante fato ter ali ocorrido. Isso não se torna, em nossa visão, motivo para a consolidação da cidade como um lugar de memória, mas não deixa de ser interessante, como mostra a figura 1 (abaixo), que o fato também não é ignorado, sendo relevante até hoje. Uma das coisas interessantes é notar que o site da prefeitura de Gaspar Alto considera a igreja adventista como um dos pontos turísticos da cidade. 5

\section{Figura 1 - Placa de Gaspar Alto como a $1^{\text {a }}$ IASD brasileira (1986)}

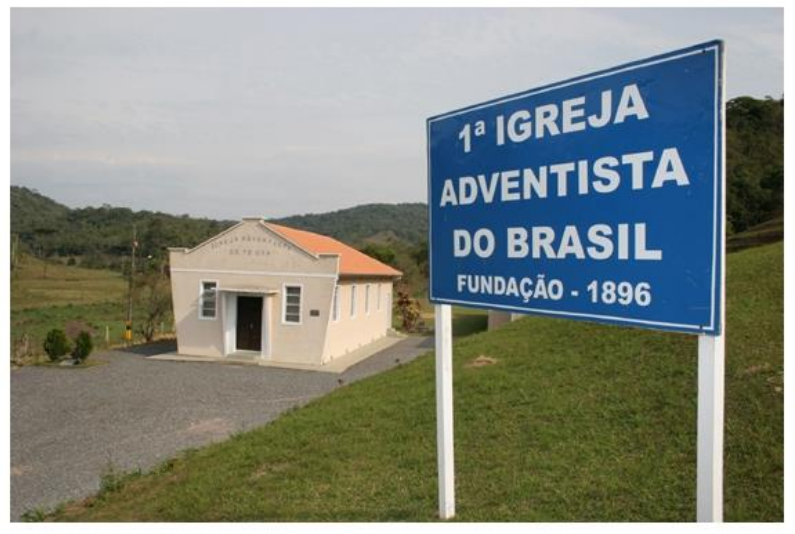

Fonte: Fotografia da pesquisa

Tanto a história da chegada do movimento ao Brasil, como a celebração de Gaspar Alto, SC, como a primeira IASD brasileira, são memorizadas na edição de Dezembro de 1924 (p. 10) da Revista Adventista. Apesar de manter a essência, é bem interessante notar as diferenças entre as histórias. Essas diferenças não inviabilizam a criação da memória identitária do movimento, apenas indicam que sua construção sempre se dá a partir de tensões, rupturas e continuidades.

${ }^{5}$ Informação do site Prefeitura de Gaspar Alto, 2018. 
Esta localidade fez sobre mim impressão especial. Gaspar Alto é a primeira e mais antiga egreja do Brasil. Em Brusque e aqui foi trazida primeiro a luz da triplice mensagem angelica no Brasil. Um jovem de nome Burchard no anno de 1878 fugiu de Brusque, tomando um vapor. Neste encontrou-se com adventistas da America do Norte. Esses irmãos indagaram do jovem se havia algum interesse pela verdade em Santa Catharina. Dois annos mais tarde, em 1880, enviaram-se revistas de Battle Creek nos Estados Unidos [...]. As revistas vinham gratuitamente dos Estados Unidos, mas o professor as vendia, gastando o prodducto em bebidas. (REVISTA ADVENTISTA, Dezembro de 1924, p. 10). ${ }^{6}$

Esse foi o único lugar de memória celebrado no Brasil que pudemos encontrar em nossa pesquisa pelas páginas da revista, mas a quantidade de visita é aparentemente pequena e não tão relevante quanto a encontrada nos EUA, o que é possível perceber na quantidade de citações encontradas e também nas publicidades espalhadas ao longo dos anos.

Para relembrar a argumentação empreendida anteriormente, discutiu-se o porquê de o local geográfico ter supremacia para justificar a continuidade religiosa. Halbwachs (1971) afirma que no espaço geográfico encontramos uma materialidade mais visível e de difícil modificação, o que transfere tais características à memória a ser recordada através dele. É possível ver, tocar e sentir seu valor como fato social. Uma religião ligada a um evento ou pessoa tem uma fragilidade maior, principalmente depois da segunda geração de crentes. Pessoas e eventos, apesar de únicos e de não se repetirem (aspectos da formação da memória religiosa), são mais efêmeros se comparados a lugares geográficos. Dado isso, poderíamos nos perguntar se teria o adventismo um local geográfico utilizado como parte da transmissão de sua memória e que poderia auxiliar tanto o evento (o desapontamento e seus desdobramentos) e a pessoa (Ellen G. White).

Parece possível afirmar que existe uma tendência de se consolidar alguns locais históricos do adventismo como pontos importantes para a concepção e consolidação da fé apregoada pelo movimento, mas em nenhum momento, pelo menos na Revista Adventista, esses locais tomam maior predominância do que os

\footnotetext{
${ }^{6}$ Foi mantida a forma original de escrita em todas as situações, respeitando o ano de sua publicação.
} 
próprios eventos e pessoas em si (tabela 1). Mas não deixa de ser interessante notarmos a tendência mais acentuada a partir de 1940, tendo um ápice em 1970, na citação da cidade de Battle Creek, local em que ocorreu a maior parte dos acontecimentos descritos no capítulo dois. Não é estranho encontrar textos como os da edição de Janeiro de 1990, na página 45, que assim narra:

Em Julho de 1886, em uma reunião campal em Michigan, o Pastor Tiago foi acometido de forte resfriado. Estava com estafa, de tanto trabalhar. Ele e a esposa estavam doentes. No dia 31 do mesmo mês, foram atacados de malária. [...] No dia 6 de agosto de 1881, com 60 anos de idade, o Pastor White dormiu na esperança da ressureição. [...] Anjos de Deus guardam aquela sepultura no cemitério de Battle Creek, em Michigan. (REVISTA ADVENTISTA, Janeiro de 1990, p. 45).

Como podemos ver, os últimos dias de vida de Tiago White, importante pioneiro do movimento, esposo de Ellen G. White e primeiro presidente da Associação Geral dos adventistas, são narrados e, no final, coloca-se o cemitério de Battle Creek como um local especial, pois ali "anjos de Deus" estariam guardando o túmulo desse pioneiro do movimento. Apesar de existir essa relação geográfica, ela é pequena se comparada as demais citações quantificadas anteriormente. Poucas são as ênfases institucionais nesses locais, tais como a necessidade deles para a ocorrência dos eventos narrados. Na maioria das vezes que se menciona um local, o foco está nos eventos e nas pessoas, esses são os que vemos serem utilizados como parte da transmissão da memória coletiva do movimento.

\section{Tabela 1 - Menções a Battle Creek na Revista Adventista (1906-2010)}

\begin{tabular}{|c|c|c|c|c|c|c|c|c|c|c|c|}
\hline Termo & 1900 & $\mathbf{1 9 1 0}$ & $\mathbf{1 9 2 0}$ & $\mathbf{1 9 3 0}$ & $\mathbf{1 9 4 0}$ & $\mathbf{1 9 5 0}$ & $\mathbf{1 9 6 0}$ & $\mathbf{1 9 7 0}$ & $\mathbf{1 9 8 0}$ & $\mathbf{1 9 9 0}$ & $\mathbf{2 0 0 0}$ \\
\hline $\begin{array}{c}\text { Battle } \\
\text { Creek }\end{array}$ & $\mathrm{o}$ & $\mathrm{o}$ & 4 & 8 & 12 & 12 & 3 & 16 & 13 & 11 & 15 \\
\hline
\end{tabular}

Fonte: Revista Adventista (1906-2010)

Assim, são poucas as citações que mostram o local como argumento que embase uma construção da memória. Um exemplo disso são os constantes alertas 
que se utilizam do "incêndio do sanatório de Battle Creek e da Review and Herald", como na edição de Maio de 1991 (p. 5). Esses eventos são lembrados como parte da fúria divina quando o povo se distância da verdade que deveria ser pregada, ou seja, a "verdade presente". O local é citado, mas não se faz como principal foco argumentativo. Poderia ter ocorrido em Battle Creek ou em outro local, o fato mais relevante é ter ocorrido no tempo dos pioneiros e ter um alerta da parte de Ellen G. White sobre como devemos nos portar para evitar que isso volte a ocorrer. Na mesma entrevista encontrada em edição de Maio de 1991 (p. 6), se demonstra claramente esse ponto. A discussão é sobre a ação social por parte da IASD e o perigo que se corre ao se perder a essência do que é ser adventista (com ênfase em 1844 e na doutrina do remanescente).

Para ilustrar esse perigo, se menciona o sanatório de Battle Creek, principalmente quando sua liderança, na pessoa do Dr. Kellogg, começa-se a tomar como prioridade a obra social e não a pregação da mensagem distintiva da igreja. Nesse momento, relembra o entrevistado, Ellen G. White escreve "tanto para o Dr. Kellogg como para a Associação Geral, dizendo claramente que o trabalho pelos pobres não deve ser prioridade da Igreja, e sim, que a prioridade da Igreja é a salvação de almas”. Não que o trabalho com os pobres não tenha seu lugar, como pode ser visto através da atuação da agência mundial mantida pela IASD para tal fim (i.e. a ADRA). O entrevistado argumenta que, cuidando-se para não perder o foco principal, existe

um chamado à Igreja Adventista, para que se preocupe mais com a comunidade. Usando o exemplo histórico de Ellen G. White e dos pioneiros, que se preocuparam com temas como a escravatura e o uso de bebidas alcoólicas, ele [um estudo citado pelo entrevistado] disse que a Igreja Adventista, histórica e biblicamente, tem todas as razões para se preocupar com a comunidade e fazer todo o possível para que este se torne melhor, apesar de sabermos que as condições perfeitas e ideais se conseguirão apenas com o estabelecimento do reino de Deus.

Assim, entende-se que a mensagem sempre tem mais importância do que os próprios pioneiros ou mesmo o espaço geográfico no qual se ocorreu os eventos a serem rememorados. Apesar de apregoarmos que a ênfase está nos pioneiros e nos 
eventos fundantes (como a menção as mensagens angélicas no texto acima), ainda assim, não deixa de ser no mínimo curioso encontrar diversas publicidades recentes, nenhuma de instituições oficiais da IASD, mas de empresas ligadas a membros da denominação, nas quais se oferecem viagens turísticas para Battle Creek. O que acontece apenas nos períodos de cinco em cinco anos, quando ocorre o encontro mundial dos adventistas, a Conferência Geral. Mas nem essa relação é constante, ocorrendo em 1989, 1990, 2000, 2010 e 2015, mas não em 1995 e em 2005 (figura 2), provavelmente devido a Conferência Geral (reunião mundial dos adventistas) não ter ocorrido, nesses anos, nos EUA. Um dos exemplos ocorre na edição de Maio de 1990 (p. 46), na qual percebemos a seguinte construção da redação publicitária:

Para a caravana de ônibus rumo à Conferência, estão previstos vinte e três emocionantes dias, onde os participantes poderão conhecer as famosas praias americanas, o Reino Mágico de Walt Disney, as cataratas de Niágara, a capital adventista do mundo, entre muitos outros pontos de interesse turístico (REVISTA ADVENTISTA, maio de 1990, p. 46).

\section{Figura 2 - Viagens para locais históricos}
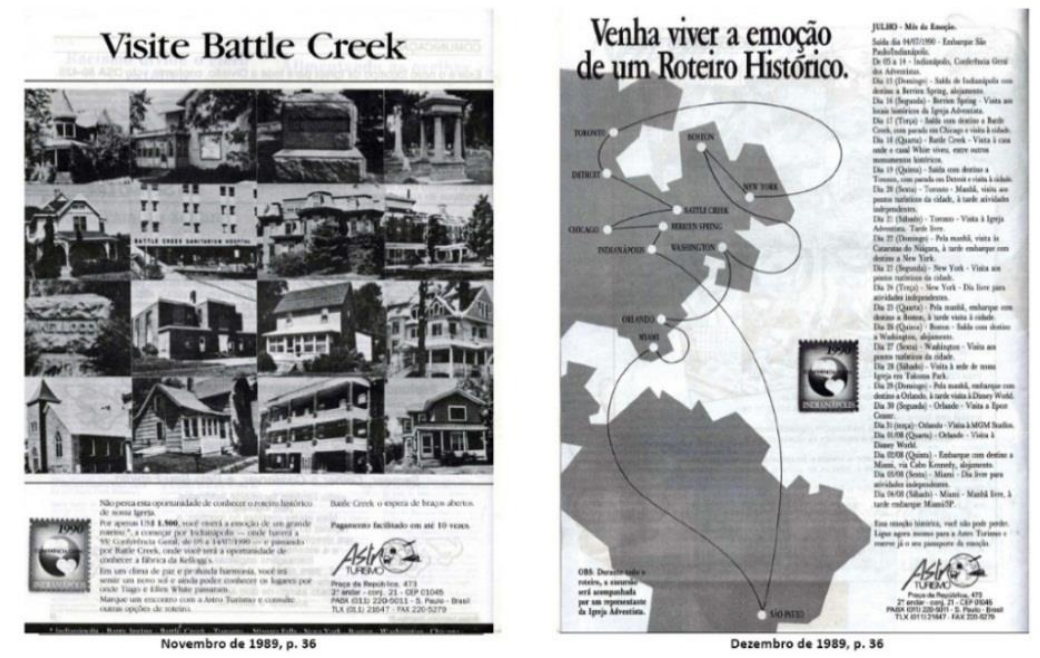


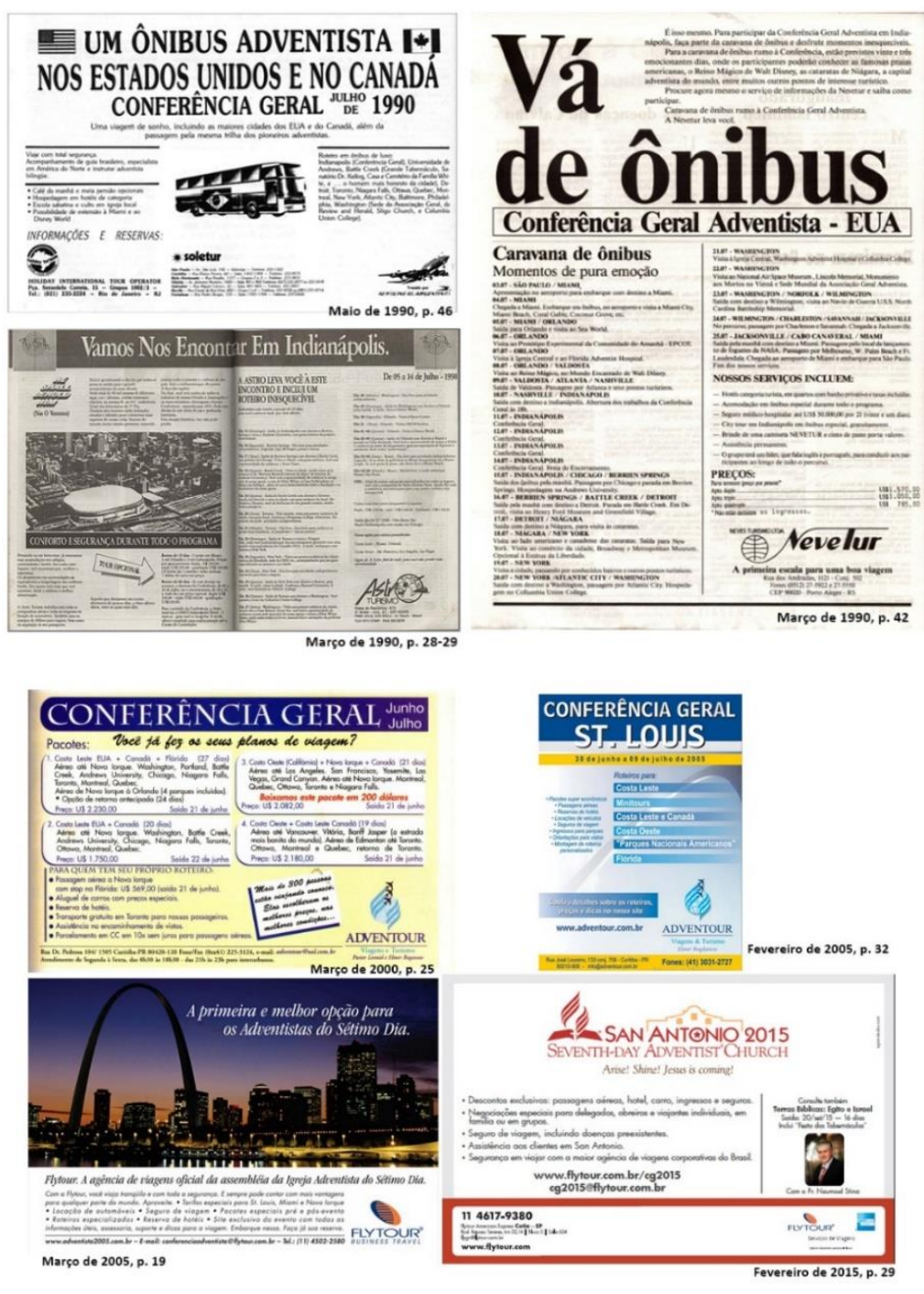

Fonte: Revista Adventista 1989-2015

É interessante que o redator do anúncio acredita que tanto Disney, Niágara como a capital adventista do mundo, no caso Battle Creek, são igualmente "pontos de interesse turístico". O que caminha na mesma direção da matéria da edição de Janeiro de 2015, intitulada "Turismo Religioso", que embora não seja inteiramente sobre os locais históricos, dando ainda mais ênfase para spas de vida saudável e mantidos pela da IASD, mostra a importância de se preservar e visitar os lugares de memória da fé adventista. 
O turismo ligado à fé vem ganhando expressividade no contexto adventista. A sede mundial da igreja conta com uma entidade que administra alguns de seus locais históricos, o Ministério da Herança Adventista (MHA), reconhecido oficialmente no início do ano passado. $\mathrm{O}$ MHA foi fundado em 1981 com a aquisição da casa de John e Betsey White [pais de Tiago White], em Battle Creek, Michigan, onde a denominação foi fundada em 1863 . O número de pessoas que visitam essa e outras propriedades que integram o patrimônio histórico adventista nos Estados Unidos é de mais de 12 mil pessoas por ano. A despeito de o turismo ligado à fé adventista ser muito mais expressivo nos Estados Unidos do que no Brasil, esse segmento também está crescendo no cenário nacional, embora menos ligado ao aspecto histórico - ainda que as opções nesse âmbito também existam. (REVISTA ADVENTISTA, Janeiro de 2015, p. 36).

O fato da reportagem acima citar que os locais históricos do adventismo receberem por ano apenas 12 mil pessoas, mostra que ainda não se consolidou tal roteiro, não sendo, possível acusar o local geográfico como constitutivo da memória do movimento. Mas como a figura 2 já indiciam, existe uma tendência rumo a isso, não como substituto da relação do fiel com a denominação, mas como algo complementar. Um exemplo mais recente é a série de vídeos postada no YouTube oficial da Revista Adventista intitulado "Reportagem mostra lugares históricos do adventismo"7, o momento escolhido para essa divulgação foi devido ao dia 22 de Outubro (data que a denominação acredita ser o seu início, em 1844) estar perto e também ao lançamento mundial de um filme intitulado "Tell the World", que narra a história do movimento (figura 3), em grande parte ocorrido em Battle Creek.

${ }^{7}$ Disponível em: <https://youtu.be/bKKUoixJs88>. Acesso em: 7/10/2016. 


\section{Figura 3 - Reportagens do filme "Tell the World" e de locais históricos}
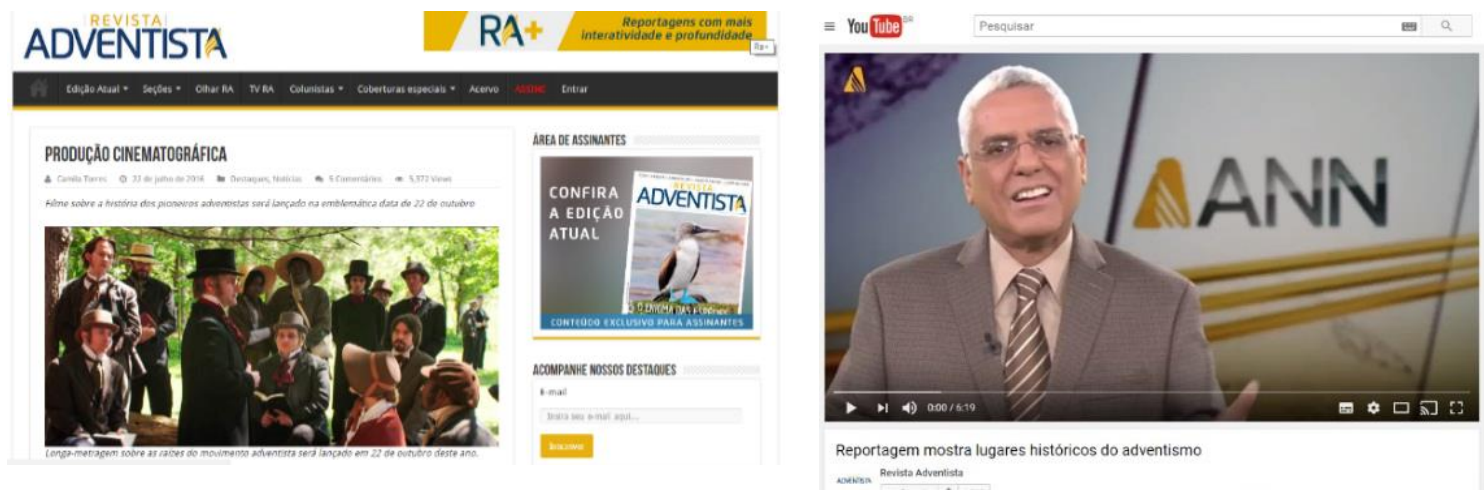

Fonte: Dados da pesquisa

É interessante notar que na reportagem disposta no YouTube e que havia passado anteriormente no programa televisivo Revista Novo Tempo, no canal televisivo oficial do movimento no Brasil, faz-se uma leve propaganda do filme e aproveita-se para mostrar alguns locais históricos, tais como a cidade de Battle Creek, a cidade de Washington, New Hampshire, assim como a casa em que Guilherme Miller (um dos precursores do adventismo, embora ele mesmo nunca tenha sido membro oficial da igreja) passou a maior parte de sua vida, atualmente ela se transformou em um museu mantido pela IASD (figura 4). Esse programa ganha certa reverberação e é também postado no site da Revista Adventista. 

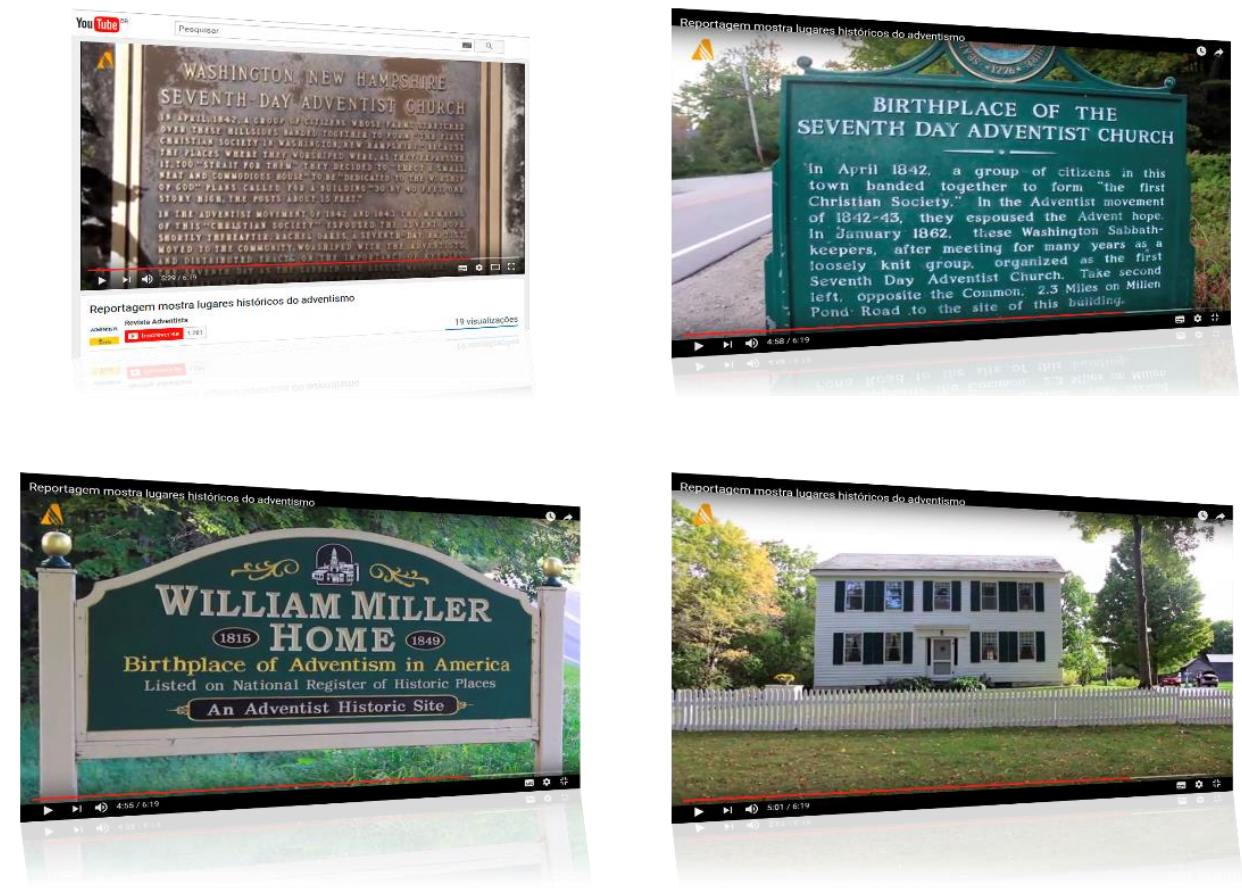

Fonte: Documentos da pesquisa

\section{Considerações gerais e finais}

Reafirmamos nossa conclusão de que não existe, pelo menos na Revista Adventista brasileira, espaço para pensar uma constituição dos quadros sociais da memória a partir de um local geográfico, pelo menos não para agora. Mas o futuro poderá indicar se a tendência que vemos na ênfase dos locais físicos permanecerá ou continuará a ser apenas um meio e não o fim da memória. Entretanto, existem fortes indícios de que esses locais servem como lugares de memória e, portanto, justificam a ênfase turística que eles recebem, ao que tudo indica, cada vez maior.

Para Dias (2003), no turismo religioso, existem dois tipos de visitantes, o peregrino puro e o visitante. Para o primeiro, a única motivação de sua viagem é de natureza religiosa, já para o segundo, há motivações diversas, que podem incluir 
a questão religiosa, mas não estão a ela restritas, existindo uma característica multifuncional. É interessante notar que as publicidades da revista (figura 2) colocam a visita para Bettle Creek como um dos locais para a viagem, que inclui também a própria ida para uma conferência geral, reunião mundial dos adventistas, e isso já, acreditamos, acaba por consolidar tal processo como parte de um evento de turismo religioso, mas longe de ser totalmente identitária e formativa tal como parece ocorrer em uma romaria ou algo do estilo.

Por outro lado, Disney e outros locais, que podem ser facilmente considerados secularizados, são disponibilizados como parte do mesmo roteiro, o que não tira a importância do local religioso como uma das opções de turismo, mas mostram a consolidação de um processo multifuncional do que propriamente de um turismo religioso puro. E isso se deve, principalmente, a relação do adventista, enquanto grupo que se considera protestante, com o texto sendo formativo para sua identidade e não um local geográfico em si. Assim, achamos difícil que a geografia um dia se torne um local constituinte da memória adventista, ficando o evento (1844 e o desapontamento) e a pessoa (Ellen G. White e outros pioneiros) como principais formas de transmissão da memória religiosa do grupo com os seus membros e futuros membros. Mas, cremos, poderá existir um aumento na importância desses lugares de memória como utilização didática por parte do movimento adventista.

\section{REFERÊNCIAS}

ALVES, R. Religião e repressão. São Paulo: Loyola, 2005.

APPOLINÁRIO, F. Dicionário de metodologia científica: um guia para a produção do conhecimento científico. São Paulo: Atlas, 2009.

BARDIN, L. Análise de conteúdo. Lisboa: Edições 70, 1977.

BAUER, M. Pesquisa qualitativa com texto, imagem e som: um manual prático. Petrópolis: Vozes, 2015. 
BORGES, M. A chegada do adventismo ao Brasil. Tatuí: Casa Publicadora Brasileira, 2001.

CAMURÇA, M. Resenha “Tradição, transmissão e emoção religiosa”. Estudos de Religião, v. 25, n. 40, p. 204-209, jan./jun. 2011.

CASADEI, E. B. Maurice e Marc Bloch em torno do conceito de memória coletiva. Revista Espaço Acadêmico, Maringá, v. 9, n. 108, maio. 2010.

COSTA, V. Comunidade virtual e comunicação: o site da Igreja Adventista do Sétimo Dia. São Bernardo do Campo, 2003. Dissertação (Mestrado em Comunicação Social) Universidade Metodista de São Paulo, 2003. Disponível em: <http://migre.me/cZDqe>. Acessado em 03/09/2012

DIAS, R. O Turismo religioso como segmento do mercado turístico. In: DIAS, R.; SILVEIRA, E. (Org.). Turismo religioso: ensaios e reflexões. Campinas: Alínea, 2003. p. 7-37.

DOUGLAS, M. Como as instituições pensam. São Paulo: EDUSP, 1998.

DURKHEIM, E. As formas elementares da vida religiosa. São Paulo: Martins Fontes, 2003a.

DURKHEIM, E. As regras do método sociológico. São Paulo: Martin Claret, 2003b.

FLICK, U. Introdução à pesquisa qualitativa. São Paulo: Penso, 2008.

FRANCO, M. O que é análise de conteúdo. São Paulo: PUC, 1986.

FOLLIS, R. Memória, mídia e transmissão religiosa: estudo de caso da Revista Adventista (1906-2010). São Bernardo do Campo, 2017. Tese (Doutorado em Ciências da Religião) - Universidade Metodista de São Paulo, São Paulo, 2017.

GILL, R. Análise de discurso. In: BAUER, M. W.; GASKELL, G. (Org.). Pesquisa qualitativa com texto, imagem e som. Petrópolis: Vozes, 2002. p. 189-217.

GODOY, A. Introdução à pesquisa qualitativa e suas possibilidades. Revista de Administração de Empresas, v. 35, n. 2, p. 57-63, mar./abr. 1995.

GREENLEAF, F. Terra de esperança: o crescimento da Igreja Adventista na América do Sul. Tatuí: CPB, 2011.

HALBWACHS, M. A memória coletiva. São Paulo: Centauro, 2009.

HALBWACHS, M. Fragmentos da la Memoria Coletctiva. Revista de Cultura Psicológica, Cidade de México, v. 1, n. 1, 1991. 
HALBWACHS, M. La topographie légendaire des évangiles en terre sainte. Paris: PUF, 1971.

HALBWACHS, M. Les cadres sociaux de la mémoire. Paris: Albin Michel, 1994.

HALBWACHS, M. Los marcos sociales de la memoria. Barcelona, Antrophos, 2004.

HERVIEU-LÉGER, D. A transmissão religiosa na modernidade: elementos para a construção de um objeto de pesquisa. Estudos de Religião, ano 14, n. 18, jun. 2000.

HERVIEU-LÉGER. Catolicismo: a configuração da memória. Rever, São Paulo, v. 5, n. 2, p. 87-107, 2005 .

HERVIEU-LÉGER. O peregrino e o convertido: a religião em movimento. Petrópolis: Vozes, 2008.

HERVIEU-LEGER, D.; WILLAIME, J. Sociologia e religião: abordagens clássicas. Aparecida: Ideias \& Letras, 2009.

MAGALHÃES, E. Análise do discurso. In: DUARTE, J.; BARROS, A. (Org.). Métodos e técnicas de pesquisa em comunicação. São Paulo: Editora Atlas, 2009.

NORA, P. Entre a memória e a história: a problemática dos lugares. Projeto História, São Paulo, v. 10, n. 2, p. 7-28, dez. 1993.

NOVAES, A.; FOLLIS, R. (Org.). O adventismo na academia brasileira: um panorama do estado da arte. Engenheiro Coelho: Unaspress, 2016.

ORLANDI, E. P. A linguagem e seu funcionamento: as formas de discurso. Campinas: Pontes, 1987.

POLLAK, M. Memória e identidade social. Estudos Históricos, Rio de Janeiro, v. 5, n. 10, p. 201-215, 1992.

POLLAK, M. Memória, esquecimento, silêncio. Estudos Históricos, Rio de Janeiro, v. 2, n. 3, p. 3-15, 1989.

PREFEITURA DE GASPAR ALTO. Foto da $1^{\mathrm{a}}$. Igreja Adventista de Gaspar Alto. 2018. Disponível em: <https://goo.gl/CPgKqv>. Acesso em: 9 fev. 2018.

REVISTA ADVENTISTA. Site. Disponível em: <http://www.revistaadventista.com.br/> . Acesso em: 9 fev. 2018.

RIBEIRO, A.; FERREIRA, L. (Org.). Mídia e memória: a produção de sentidos nos meios de comunicação. Rio de Janeiro: Mauad X, 2007. 
RIOS, F. Memória coletiva e lembranças individuais a partir das perspectivas de Maurice Halbwachs, Michael Pollak e Beatriz Sarlo. Revista Intratextos, Rio de Janeiro, v. 5, n. 1, p. 1-22, 2013.

RIVERA, D. P. B. Matrizes protestantes do pentecostalismo. In: PASSOS, J. D.

Movimentos do Espírito: matrizes, afinidades e territórios pentecostais. São Paulo: Paulinas, 2005.

RIVERA, D. P. B. O demônio e o protestantismo no mundo em desencantamento. Estudos de Religião, ano 21, n. 33, p. 42-58, jul./dez. 2007.

RIVERA, D. P. B. Religião e tradição a partir da sociologia da memória de Maurice Halbwachs. Numen: revista de estudos e pesquisa da religião, Juiz de Fora, v. 3, n. 1, p. 69-94, 2010b.

RIVERA, D. P. B. Tradição, transmissão e emoção religiosa: sociologia do protestantismo na América Latina. São Paulo: Olho d’Água, 2010a.

ROCHA, D.; DEUSDARÁ, B. Análise de conteúdo e análise do discurso: aproximações e afastamentos na (re)construção de uma trajetória. Alea, v. 7, n. 2, p. 305-322, dez. 2005.

SANTOS, M. S. Memória coletiva e teoria social. São Paulo: Annablume, 2003.

SCHÜNEMANN, H. E. S. O Tempo do fim: uma história social da Igreja Adventista do Sétimo Dia no Brasil. 2002. São Bernardo do Campo, 2002. Tese (Doutorado em Ciências Sociais e Religião) - Universidade Metodista de São Paulo, São Paulo, 2002.

SCHWARZ, R. W; GREENLEAF, F. Portadores de luz: história da Igreja Adventista do Sétimo Dia. Engenheiro Coelho: Unaspress, 2016.

STRAUSS, A.; CORBIN, J. Pesquisa qualitativa: técnicas e procedimentos para o desenvolvimento de teoria fundamentada. São Paulo: Artmed, 2008.

WILSON, V. Modos de ler o discurso religioso. Soletras, São Gonçalo: UERJ, ano 3, n. 56, 2003. Disponível em: <http://bit.ly/2nUplo3>. Acesso em: 25 jan. 2008. 